\title{
Head injuries related to birth trauma among low birthweight neonates during vacuum extraction: a retrospective cohort study
}

\author{
Gal Cohen ${ }^{1}$, Hanoch Schreiber ${ }^{1}$, Nir Mevorach ${ }^{1}$, Gil Shechter Maor ${ }^{1}$, ofer Markovitch ${ }^{1}$, and \\ Tal Biron-Shental ${ }^{1}$ \\ ${ }^{1}$ Meir Medical Center
}

October 2, 2021

\begin{abstract}
Objective: Prematurity [gestational age $(\mathrm{GA})<34 \mathrm{w}$ ] is a relative contraindication to vacuum extraction (VE). Current data do not discriminate clearly between prematurity and low-birthweight (LBW). We aimed to evaluate the impact of non-metal vacuum cup extraction on neonatal head injuries related to birth-trauma (HI), among newborns with LBW $(<2,500 \mathrm{~g})$. Design: A retrospective cohort. Population: 3,335 singleton pregnancies, delivered by VE from 2014 to 2019. All were $>34 \mathrm{w}$ GA. Methods: We compared 207 (6.2\%) neonates with LBW <2,500g to 3,128 (93.8\%) neonates with higher BW, divided into 3 subgroups $(2,500-2,999 \mathrm{~g}, 3,000-3,499 \mathrm{~g}$, and $>3,500 \mathrm{~g})$. Main outcome measures: HI and other neonatal complications. Results: The lowest rates of subgaleal hematoma occurred in neonates $<2,500 \mathrm{~g}(0.5 \%)$ and increased with every additional $500 \mathrm{~g}$ of neonatal birthweight $(3.2 \%, 4.4 \%$ and $7.6 \%$ in $2,500-2,999 \mathrm{~g}, 3,000-3,499 \mathrm{~g}$, and $>3,500 \mathrm{~g}$ groups, respectively; $\mathrm{p}=0.001)$. Fewer cephalohematomas occurred among LBW neonates $(0.5 \%$ in $<2,500 \mathrm{~g})$ and increased with every additional $500 \mathrm{~g}$ of birthweight $(2.6 \%, 3.3 \%$ and $3.8 \%$ in $2,500-2,999 \mathrm{~g}, 3,000-3,499 \mathrm{~g}$, and $>3,500 \mathrm{~g}$ groups, respectively, $\mathrm{p}=0.026)$. Logistic regression found increasing birthweight as a significant risk-factor for head injuries during VE, with adjusted odds ratios of 8.874, 10.624, 13.980 for $2,500-2,999 \mathrm{~g}, 3,000-3,499 \mathrm{~g}$, and $>3,500 \mathrm{~g}$, respectively $(\mathrm{p}=0.015)$. NICU hospitalization rates were highest among neonates weighing $<2,500 \mathrm{~g}(10.1 \%)$ compared to the other groups $(2.7 \%, 1.7 \%$ and $3.3 \%$ in $2,500-2,999 \mathrm{~g}, 3,000-3,499 \mathrm{~g},>3,500 \mathrm{~g}$ respectively, $\mathrm{p}=0.000)$. Conclusions: $\mathrm{VE}$ of neonates weighing $<2500 \mathrm{~g}$ at $34 \mathrm{w}$ and beyond seems as a safe mode of delivery when indicated, with lower rates of HI, compared to neonates with higher BW. Funding: none.
\end{abstract}

\section{Hosted file}

Vacuum LBW_Article_BJOG_09.2021_final.docx available at https://authorea.com/users/439042/ articles/540093-head-injuries-related-to-birth-trauma-among-low-birthweight-neonatesduring-vacuum-extraction-a-retrospective-cohort-study 